\title{
Técnicas Reexpansivas No Derrame Pleural - Uma Revisão De Literatura
}

\section{Re-expansion techniques in pleural effusion: a review}

\author{
Cleize Silveira Cunha ${ }^{1}$ \\ Bruno Soares ${ }^{2}$ \\ Ramon Rocha Nascimento ${ }^{3}$
}

Artigo

Original

Original

Paper

\section{Palavras-chaves: \\ Derrame pleural \\ Líquido pleural \\ Expansão \\ pulmonar}

Resumo

O derrame pleural se caracteriza pelo acúmulo de grande quantidade de líquido no espaço pleural, podendo ser caracterizado como patologia primária ou secundária, é análogo ao líquido de edema nos tecidos. Geralmente, evolui com dor localizada, em correspondência com a zona lesada; tosse irritante e tímida, não produtiva; dispneia, dependendo da quantidade do derrame; febre; redução do movimento da parede torácica; deslocamento do mediastino para o lado oposto; diminuição do frêmito tóraco-vocal (FTV); som maciço a percussão; diminuição do murmúrio vesicular e níveis hidroaéreos no exame radiológico.

A fisioterapia atuará, de forma a promover a reexpansão da área afetada, aumentando assim, a ventilação alveolar e diminuindo a hipoventilação.

As principais técnicas analisadas foram: posicionamento no leito, controle postural, conscientização diafragmática, estimulação proprioceptiva do diafragma e direcionamento de fluxo.
Abstract

Pleural effusion means large amount of liquid in the pleural space. It could be caused by a primary or secondary disease process and it seems oedema of interstitial tissue. The symptoms more prevalent are located pain, corresponding to the injury area, cough without expectoration, fever, impairement chest wall motion, mediastinum compressing, decreasing breath sounds, impaired percussion notes, collections of pleural air and fluid.Dyspnea can be associated with the amount of the pleural effusion.

The physiotherapy can perform a number of thecniques to promote aeration of injuried area increasing gas exchange and decreasing hypoventilation.

The appropriate techiniques analized in this work are bedside positioning of the patient,postural control,diaphragmatic synchronized stimulation and airflow direction.
Key words:

Pleural effusion

Position of the

patient

Expansion

pulmonary

\section{Introdução}

Segundo GOLDMAN e AUSIELLO (2005), o derrame pleural caracteriza-se, pelo acúmulo de grande quantidade de líquido no espaço pleural, podendo ser identificado como patologia primária ou secundária, é análogo ao líquido de edema nos tecidos. Geralmente, evolui com dor localizada, em correspondência com a zona lesada; tosse irritante e tímida, não produtiva; dispnéia, dependendo da quantidade do derrame; febre; redução do movimento da parede torácica; deslocamento do mediastino para o lado oposto; diminuição do frênico tóraco-vocal (FTV); som maciço a percussão; diminuição do murmúrio vesicular e níveis hidroaéreos no exame radiológico.

O fisioterapeuta, em seu tratamento,

\footnotetext{
Fisioterapeuta Mestranda em Terapia Intensiva pela UFRJ, Professora do Curso de Fisioterapia do UNIFOA. 
objetivará promover, entre outras coisas, o aumento da drenagem do líquido (paciente com dreno), incentivar a expansão pulmonar, melhorarmobilidadetorácica, removersecreção pulmonar, melhorar a função diafragmática, evitar posturas antálgicas, realizar orientações posturais, observar drenagem torácica, evitar entubação oro-traqueal e ter cuidados com o dreno. Como no tratamento do derrame pleural, a principal forma de tratamento ocorre por meio de técnicas reexpansivas, elegemos, em nossa revisão bibliográfica, algumas técnicas. São elas: Posicionamento no leito, controle postural, conscientização diafragmática, estimulação proprioceptiva do diafragma e direcionamento de fluxo.

Temos como proposta, analisar neste trabalho, através da revisão bibliográfica, as diversas técnicas reexpansivas e seus objetivos no tratamento do derrame pleural.

\section{Desenvolvimento}

O derrame pleural constitui uma manifestação comum de comprometimento pleural tanto primário quanto secundário. Em condições normais, a superfície pleural é lubrificada por não mais de $15 \mathrm{ml}$ de líquido claro e seroso, relativamente acelular. Ocorre acúmulo aumentado de líquido pleural em cinco situações: Aumento da pressão hidrostática, como ocorre na insuficiência cardíaca congestiva; aumento da permeabilidade vascular, como na pneumonia; redução da pressão oncótica, como na síndrome nefrótica; aumento da pressão negativa intrapleural, como na atelectasia; diminuição da drenagem linfática, como na carcinomatose mediastinal (ROBBINS, 2000).

Segundo CARVALHO (2001), é um espaço virtual, revestido por membrana serosa de origem mesodérmica.

Conforme GOLDMAN E ANSIELLO (2005), a pleura consiste em uma camada de células mesoteliais com uma aparência transparente e lisa. È apoiada por uma rede de tecido conjuntivo fibroelástico, linfáticos e vasos. As células mesoteliais são ricas em microvilosidades e sua função mais importante é liberar glicoproteínas ricas em ácido hialurônico para diminuir o atrito entre o pulmão e a parede torácica. A pleura parietal cobre a superfície da parede torácica, diafragma e mediastino. È suprida de sangue pela circulação sistêmica e contém nervos sensoriais. A pleura visceral cobre a superfície dos pulmões, inclusive as fissuras interlobares; seu suprimento sanguíneo é proveniente da circulação pulmonar de baixa pressão e não tem nervos sensitivos. As duas camadas são separadas por uma cavidade virtual, que é lubrificada por 5 a $10 \mathrm{ml}$ de líquido, facilitando, assim, a expansão pulmonar e ajudando a manter a insuflação pulmonar por acoplar-se à parede torácica.

O líquido pleural tem uma baixa concentração de proteína $(<2 \mathrm{~g} / \mathrm{dl})$ com um valor de $\mathrm{pH}$ e de glicose similar ao do sangue. O líquido pleural é formado principalmente pela pleura parietal, e parte de sua renovação depende das mesmas forças de Starling que governa as trocas de líquido vascular e intersticial. A pleura parietal tem uma pressão hidrostática similar à da circulação sistêmica (30 cm H2O), enquanto a pleura visceral dependa da circulação pulmonar $(10 \mathrm{~cm}$ $\mathrm{H} 2 \mathrm{O}$ ). A pressão oncótica é similar em ambas (25 cm H2O), mas a pressão na cavidade pleural é afetada pelo gradiente de gravidade. Portanto, o espaço pleural é heterogêneo com uma porção não dependente, na qual as forças de Starling favorecem a efusão dos líquidos para a cavidade e para dentro dos capilares parenquimatosos. Os estomas, ou "lacunas"que estão presentes sobre a superfície parietal da porção baixa do mediastino, porção baixa da parede torácica e diafragma - parecem se esvaziar para os linfáticos. Estes linfáticos subpleurais representam uma via importante para a drenagem dos líquidos e solutos. As alterações desse mecanismo de formaçãoreabsorção, frequentemente, resultam no acúmulo de líquido pleural. Aumentos nas forças hidrostáticas ou diminuições nas pressões oncóticas resultam em transudatos. A maior efusão através dos capilares ou células e/ ou bloqueio dos linfáticos resulta em exudatos (GOLDMAN E AUSIELLO, 2005).

De acordo com PAULA (1984), a classificação do derrame pleural varia segundo sua etiologia e pode ser dividido em 6 grandes grupos que são:

A) Infecção: Bacterianas, viróticas, micóticas, protozooses;

B) Insuficiência cardíaca congestiva;

C) Neoplasias:

Primárias - mesotelioma local benigno e mesoteliomas difusos malignos, 
Secundárias - carcinoma broncogênico, carcinoma da mama e linfonas;

D) Hipoproteinemias: cirrose e síndrome nefrótica;

E) Colagenoses

F) Outras causas:

Pulmonares - infarto pulmonar, derrame estéril das pneumonias, síndrome de Loeffler e sarcoidose,

Torácicas - traimatismo e metástase da parede e hemopneumotorax,

Subdiafragmáticas $\quad-$ abcesso subfrênico, pancreatite e síndrome de Meigs.

Os grupos descritos foram citados apenas para se ter uma visão geral dos tipos de derrame pleural.

Segundo CARVALHO (2001), a dor súbita e intensa no lado afetado é o primeiro sintoma em $80 \%$ dos casos. Ela resulta do atrito entre os dois folhetos, durante os movimentos respiratórios, piorando pela distenção da pleura parietal inflamada. $\mathrm{Na}$ respiração profunda, tosse, flexão ou extensão da coluna verbal, etc., ela se torna mais intensa.

Segundo GOLDMAN AUSIELLO (2005), a dor, em geral, é unilateral e aguda, e piora com a inspiração ou tosse. Ela pode irradiar para ombro, pescoço ou abdome. A dispneia pode resultar da compressão do tecido pulmonar e de alterações mecânicas nos músculos respiratórios à medida que o líquido muda a sua relação comprimento-tensão. O grau de dispneia relaciona-se com o volume de líquido e com a pressão intratorácica e seu efeito sobre a mecânica e a troca gasosa. Os derrames pleurais, em pacientes com comprometimento pulmonar mínimo, são bem tolerados, enquanto os derrames similares, em pacientes com doença pulmonar, podem causar insuficiência ventilatória.

\section{Aspectos radiográficos}

O espaço pleural , embora normalmente vazio e colapsado, pode conter líquido ou ar, ou ambos, qualquer dos quais irá alterar o aspecto do filme de tórax. Uma coleção maciça de líquido em um lado pode deslocar o mediastino em direção ao lado oposto, deprimir o diafragma, colapsar parcialmente o pulmão e tornar todo o hemitórax denso e branco. (NOVELINE, 1999)

Grandes quantidades de líquido pleural são fáceis de visualizar; pequenas quantidades são muito mais difíceis.

O seio (ou sulco) costofrênico,

do qual somente a parte lateral aparece na radiografia de tórax $\mathrm{PA}$, é uma depressão contínua formada entre a parede torácica e o diafragma. A parte mais baixa dessa depressão, quando o paciente fica sentado ou de pé, está localizada bem posteriormente de cada lado da coluna.

Nessa depressão, estende-se a base de cada lobo inferior contra o segmento posterior do diafragma, e o líquido pleural gravita nela. Assim, os primeiros mililitros de líquido pleural que se acumularem podem não ser visíveis no sulco costrofênico lateral na radiografia de tórax PA do adulto, mas seriam vistas em uma radiografia lateral de tórax, obscurecendo a porção posterior do diafragma.

Quando líquido suficiente está presente para encher o sulco posterior, a parte lateral do sulco começa a encher, e isto será notado na radiografia de tórax PA como um borramento ou obliteração do seio costofrênico daquele lado. (NOVELINE, 1999)

Normalmente, as projeções mas indicadas para se ter uma imagem satisfatória para análise de derrame pleural são as de PA, perfil e decúbito lateral.

\section{Tratamento Fisioterápico}

Fundamentos da terapia de expansão pulmonar

De acordo CARVALHO (2001), a Fisioterapia só será iniciada no derrame pleural quando indicada e dependerá das doenças que o originam. A Fisioterapia respiratória visará a reexpansão da área afetada por meio de manobras e padrões respiratórios da cinesioterapia, no decúbito determinado, com restauração da ventilação.

Segundo PRESTO (2006), as técnicas de expansão pulmonar constam de uma série de manobras fisioterápicas com objetivo de aumentar a ventilação alveolar e diminuir a hipoventilação, especificamente em doenças da pleura como o derrame pleural, favorecendo assim, as trocas gasosas através do posicionamento no leito e após a drenagem dos derrames, tendo como objetivo expandir os alvéolos previamente colapsados. 
As técnicas de expansão pulmonar são técnicas fisioterápicas que podem ser realizadas através de manobras manuais, manobras orientadas pelo fisioterapeuta e manobras com a utilização de aparelhos (PRESTO, 2004). De acordo com TARANTINO (2002), essas técnicas vão atuar em regiões pulmonares hipoventiladas ou evitar a hipoventilação, fazendo com que ocorra uma expansão dessas regiões, através do aumento do volume pulmonar.

O volume pulmonar aumenta em decorrência da técnica de expansão pulmonar provocar um aumento no gradiente de pressão transpulmonar (diferença entre as pressões pleural e alveolar), sendo assim, quanto maior o gradiente de pressão transpulmonar, maior será a expansão alveolar.

Para a aplicação das técnicas de expansão pulmonar, alguns pré-requisitos são necessários para que seja aplicada a técnica mais adequada, de acordo com a individualidade de cada paciente. Esses pré-requisitos são: exame físico, ausculta pulmonar, radiograma de tórax, gasometria arterial e eletrocardiograma.

Todas as técnicas são importantes, desde que se tenha o paciente certo, o momento clínico adequado e os objetivos firmados (AZEREDO, 2002).

Posicionamento no Leito / Controle Postural:

Essa técnica é aplicada em pacientes acamados, e caracteriza-se como mudança de decúbitos, que são posicionamentos variáveis no leito de acordo com o pulmão acometido.

A técnica é simples, porém, deve ser realizada corretamente e com alguns cuidados, como mudança de decúbito, no máximo a cada duas horas, para evitar úlceras de decúbito (escaras), durante o posicionamento de pacientes incapazes de movimentar seus membros ativamente, deve ser colocado na posição funcional de cada membro específico, se não for possível, o posicionamento deve ser o mais próximo do funcional e por último deve-se ter um posicionamento ideal do leito. A evolução motora e respiratória de pacientes acamados depende diretamente da utilização correta dessa técnica.

\section{Decúbito dependente:}

O decúbito que o paciente vai adotar tem o nome do segmento corporal que se encontra no leito, e este será denominado de decúbito dependente. Temos os seguintes decúbitos: decúbito dorsal ou posição supina, decúbito ventral ou posição prona e decúbito lateral direito ou esquerdo. Alguns autores citam uma posição alternativa ao decúbito lateral, que é o decúbito lateral parcial (semidecúbito lateral).

\section{Controle/ Conscientização Diafragmática:}

Conforme PRESTO (2004), durante a aplicação desta técnica, o paciente deve estar deitado ou sentado, o Fisioterapeuta deve colocar as duas mãos acima do final do apêndice xifoide e realizar incursões ventilatórias, de forma que suas mãos elevemse durante a inspiração e deprimam-se durante a expiração.

Existem algumas posições em que a mecânica diafragmática está favorecida como por exemplo: sentar-se com o tronco inclinado para frente, pois, dessa forma, a musculatura abdominal tende a criar uma zona de aposição ao diafragma, favorecendo sua contração.

\section{Estimulação/ Propriocepção Diafragmática:}

Durante a aplicação dessa técnica, o paciente deve estar, de preferência, deitado. O fisioterapeuta realizará a técnica posicionando suas mãos na parte superior da região epigástrica, durante os movimentos ventilatórios do paciente, e realizar estímulos para baixo e para dentro em direção ao diafragma.

\section{Direciona de fluxo / ventilação seletiva}

Segundo PRESTO (2004), essa técnica é a mais controversa da Fisioterapia respiratória. Ela consiste em posicionar a cabeça do paciente em rotação e lateralização para a direita ou esquerda, e ao mesmo tempo, o terapeuta realiza uma pressão em um dos hemitórax. Um exemplo prático é se o Fisioterapeuta desejar direcionar o fluxo para o pulmão direito, a cabeça do paciente deverá estar posicionada em rotação e lateralização para a esquerda, e deve ser realizada uma compressão no hemitórax esquerdo do paciente. Porém, essa 
técnica ainda é muito questionável em relação a sua eficácia.

\section{Considerações Finais}

As técnicas de reexpansão pulmonar têm uma fundamentação teórica consistente, quando se trata de sua aplicação em pacientes acometidos por derrame pleural, já que no derrame pleural ocorre um aumento no líquido pleural fazendo com que diminua a expansibilidade dos pulmões e, algumas vezes, até mesmo da caixa torácica, causando assim, uma diminuição na ventilação dos alvéolos, ou seja, uma hipoventilação alveolar.

As técnicas fisioterápicas de reexpansão têm como objetivo o aumento do volume de ar nos alvéolos, diminuindo assim a hipoventilação alveolar, fazendo com que os sinais e sintomas diminuam ou, até mesmo, desapareçam no paciente acometido por essa doença.

Para a aplicação das técnicas de reexpansão deve-se levar em consideração o estado clínico e os exames complementares do paciente, pois, essas técnicas só devem ser aplicadas após a drenagem do paciente, isso quando a drenagem for necessária.

Estatísticamente, não encontramos dados sustentáveis para definirmos, com propriedade, uma característica uniforme de pessoas com derrame pleural. Assim como, grau, número e gênero frente a tanta diversidade de causas.

Em análise radiográfica, percebemos que as projeções que podem ter maior clareza para análise são PA, perfil e DL.

Contudo, cabe ao fisioterapeuta escolher as técnicas mais adequadas para cada tipo de paciente, aplicando-as no momento certo e de forma correta, provavelmente, o profissional alcançará resultados satisfatórios no tratamento do derrame pleural através das técnicas de reexpansão pulmonar.

\section{Referências Bibliográficas}

AZEREDO, Carlos Alberto Caetano Machado. RODRIGUES, Maria da Glória. Fisiotarapia respiratória moderna. Ed. $4^{\circ}$, São Paulo: Editora Manole, 2002.

CARVALHO, Mercedes. Fisioterapia respiratória. Fundamentos e contribuições. Ed. 5a, Rio de Janeiro: Editora Revinter, 2001.

COTRAN, Ranzi S., KUMAR, Vinay, COLLINS, Tucker. Patologia estrutural e funcional. Ed. 6 ${ }^{\mathrm{a}}$, São Paulo: Guanabara Koogan, 2000.

GOLDMAN, Lee, AUSIELLO, Dennis. Tratado de medicina interna. Ed. 22a , São Paulo: Editora Elsevier, 2005.

****COSTA, Dirceu. Fisioterapia respiratória básica. Rio de Janeiro: Atheneu, 1999.

****MACKENZIE, Colin F. et al. Fisioterapia respiratória em unidade de terapia intensiva. São Paulo: Panamericana, 1988.

PAUlA, Aloysio. Pneumologia. Ed. 1'a , São Paulo: Sarvier, 1984.

PRESTO, Bruno, PRESTO, Luciana Damázio de Noronha. Fisioterapia na UTI. Ed. $1^{\text {a }}$, Rio de Janeiro: Editora BP, 2006.

PRESTO, Bruno, PRESTO, Luciana Damázio de Noronha. Fisioterapia respiratória: Uma nova visão. Ed. $2^{\mathrm{a}}$, Rio de Janeiro: Editora BP, 2005.

****PRYOR, Zenrifer. WEBBER, A. Barbara. Fisioterapia para problemas respiratórios e cardíacos. Ed. 2a , Rio de Janeiro: Guanabara Koogan, 2002.

ROBBINS, Stanley. COTRAN, Ranzis. KUMAR, Vinay. COLLINS, Tucker. Fundamentos de Robbins: Patologia estrutural e funcional. Ed. $6^{\text {a }}$, Rio de Janeiro: Guanabara Koogan, 2001.

Endereço para Correspondência:

Cleize Silveira Cunha

mariangela.schetino@foa.org.br

Ramon Nascimento

nascimento.ramon@hotmail.com

Centro Universitário de Volta Redonda

Campus Três Poços

Av. Paulo Erlei Alves Abrantes, $n^{\circ}$ 1325,

Três Poços - Volta Redonda / RJ

CEP: $27240-560$ 